\title{
El museo desde el artista: estrategias institucionales en Lima y Buenos Aires
}

\author{
Agustín Díez Fischer
}

$\Lambda$ lo largo de todo el siglo Xx, los artistas nunca consideraron el museo como mero lugar de exhibición. Más aún: esta institución se ha visto como espacio de poder, objeto de denuncia, de intervención o, tal cual lo entendieron los futuristas, como enemigo directo, merecedor de su completa destrucción. América Latina no ha sido la excepción: en este trabajo tomaremos dos contextos urbanos disímiles, como lo son Buenos Aires y Lima, para poner en relación un conjunto particular de prácticas que se apropiaron de la noción de museo de arte para redimensionar su sentido y proponer modelos museológicos alternativos.

Estas estrategias se enfrentan a una realidad museal donde la instituciónmuseo arte contemporáneo no está consolidada ni posee la fuerza legitimadora que tiene en los países del centro, que, por el contrario, dialogan con una "inscripción mimética/colonial/derivativa de la institución" que aparece en los países hegemónicos (Medina 2002: 2). En un lugar intermedio entre los proyectos de gestión y la producción artística, algunos autores se han referido a ellos como prácticas pseudoinstitucionales, en tanto que, en un "juego irónico/mimético/sucedáneo, focalizan las limitaciones de la institución-museo y la institución-arte en un cierto contexto, como plataforma de exploración estético/político/cultural" (idem).

Estos procedimientos se han denominado museotopías, concepto desarroIlado fundamentalmente en el contexto peruano, donde, ante la ausencia de un museo de arte contemporáneo, o de arte moderno, los artistas empiezan a crear instituciones museales alternativas $y$, con ello, redimensionan la noción misma de "museo". En tanto prácticas instituyentes, como las entiende Gerald Raunig (2009), es significativo ponerlas en relación con las estrategias que hemos elegido para el caso de Buenos Aires, toda vez que allí los museos existentes son intervenidos para ser resignificados en sus objetivos, estructura y funcionamiento. En este sentido, son pertinentes las palabras de Gustavo Buntinx (2006a: 221), puesto que estas estrategias, más que plantear una cuestión museográfica, presentan un problema propiamente museológico de construcción de sentido: "That broad conception, historically founded and critically empowered, is where museology defines its own distinct realm as a construction of meaning". 
Unos años atrás, Hal Foster (2001: 107) se preguntaba cómo la pintura neogeo podía, con un medio preindustrial, afrontar problemáticas que desafiaban a la sociedad postindustrial. Este artículo surge de un cuestionamiento similar, al preguntarnos por qué en el contexto latinoamericano una institución tan asociada a la modernidad, lejos de mermar su importancia como espacio de circulación, es revalorizada desde producciones artísticas contemporáneas que plantean modelos alternativos, donde el museo se construye para responder a un papel político y cultural concreto. No se trata de regresar al museo, "sino de completar la idea de musealidad, que quedó trunca en el momento en que los poderes públicos favorecieron su ruinificación" (Mellado 2003: 51).

\section{El museo y la crítica}

La historia de los museos ha estado fuertemente vinculada con el proceso de consolidación del Estado-nación. Esta relación se ha teorizado en función del papel que han cumplido estas instituciones como "poderosas máquinas de definición de identidad" (Duncan 1991: 102). Así, en América Latina, muchos de los museos nacionales se crearon a finales del siglo XIX durante los procesos de consolidación de los noveles países. Los museos asumieron entonces un papel fundamental en la "reconstrucción y apropiación de un pasado común que se convierte en la base de su visión de destino colectivo" (Smith 1997: 172). Este mismo papel puede observarse, por ejemplo, en la importancia que tuvieron los museos en los festejos de los centenarios latinoamericanos en las primeras décadas del siglo XX.

Sin embargo, no será sino hasta finales de los años sesenta y principios de los setenta de ese siglo cuando se desarrolle una serie de textos críticos que denuncien esta vinculación entre el poder nacional y los museos de arte. Dentro del amplio espectro de producciones, cabe destacar el aporte de Bourdieu (2003), quien definió el papel de los museos como instituciones fundamentalmente de exclusión y división. En el ámbito de la tradición marxista, también resultaron muy significativas las aportaciones fundantes de la museología crítica, elaboradas por Carol Duncan y Alan Wallach $(1978,1980)$. Sus estudios desmitificaron la supuesta neutralidad política de los museos, y comprobaron cómo el ritual de asistencia a las exposiciones estaba fuertemente vinculado con un proceso de legitimación del Estado. El museo reforzaba entonces las distinciones entre lo elitista y lo popular, entre alta y baja cultura o entre el ciudadano y el extranjero.

En el marco de estos desarrollos teóricos, algunos artistas empezaron a orientar sus obras hacia estas problemáticas. Benjamin Buchloh (1990) estableció el canon historiográfico de la crítica institucional remontándose a las prácticas de Michael Asher, Robert Smithson, Daniel Buren, Hans Haacke y Marcel Broodthaers. Esta "primera generación" limitó su accionar específicamente a la crítica de la institución-museo (Holmes 2007) y cuestionó su papel autoritario a partir de tres estrategias: la negación radical de las instituciones en su conjunto, y el intento de construir otras alternativas, y de interferir en las instituciones dominantes (Steyerl 2006). Para Hal Foster (2001: 16) estas estrategias sometieron a las instituciones artísticas a un análisis deconstructivo, complejizando y no meramente repitiendo - como sostendría Bürger (1997: 54-55) — las operaciones críticas de las vanguardias históricas.

Un antecedente pertinente para el ámbito latinoamericano lo constituye el estudio de Stefan Nowotni (2006), quien remarca cómo a finales de los ochenta y principios de los noventa las prácticas de la denominada "segunda ola de crítica institucional" problematizaron la influencia de las políticas neoliberales en el museo y la vinculación de los factores trasnacionales en los procesos museísticos. Por otra parte, Andrea Fraser (2005) ha sostenido que en los últimos años estas prácticas han virado hacia la creación de instituciones críticas establecidas mediante el autocuestionamiento y la autorreflexión, donde las disertaciones sobre el museo parecen Ilevarlas a cabo principalmente los curadores y directores, antes que los artistas. Esto resulta interesante en tanto las museotopías latinoamericanas representan estrategias de formación mixta, donde la figura del artista, del gestor y del curador no se diferencian claramente.

Las críticas clásicas al museo suponen un proceso vertical de formación de identidad, donde la institución cumple un papel articulador entre las élites, que "imponen" diversos mecanismos de representación o códigos de conducta al resto de la población. Al mismo tiempo, se propone un proceso de homogeneización cultural que, a pesar de las diferencias entre los distintos sectores de la sociedad, haga posible conformar lo nacional. Ahora bien, este modelo vertical, que ya ha sido criticado por Clifford Geertz, no permite incorporar al análisis los vectores horizontales en los mecanismos de formación de identidad nacional.

La década de 1990 y los procesos neoliberales, tal cual lo plantea Walter Connor (1998), están en gran parte configurados por el fracaso de esa relación vertical, no simplemente respecto de la formación de una identidad nacional —compleja en las sociedades latinoamericanas-, sino también en cuanto a la desarticulación de los mecanismos de identificación con el Estado. Estos procesos de liberalización dieron lugar a que gran parte de la población, que había tenido su función en la antigua estructura, no pudiera adaptarse a la nueva situación social y conformara así un grupo excluido, sin la contención del antiguo sistema ni la posibilidad de insertarse en el nuevo perfil del sector privado.

Es necesario, entonces, buscar estrategias de análisis capaces de abordar ciertos procesos microinstitucionales que reflexionen sobre $-y$ ante- la desarticulación de las identidades nacionales y estatales. En este sentido, las 
museotopías y las diversas respuestas institucionales se constituyen como un desafío que ofrece un acercamiento a estas problemáticas latinoamericanas comunes, aunque respondan a contextos no necesariamente idénticos.

En este marco, al poner en circulación conjuntos iconográficos desplazados, estos proyectos artísticos empiezan a configurarse como estrategias de vinculación entre el individuo, o grupos específicos y la sociedad. Estas prácticas se posicionan sobre esta fractura, esta falta de integración social, y a partir de este lugar los artistas convierten una institución eminentemente moderna en un mecanismo crítico. Eva Grinstein (citado en Mellado 2003: 50) ha puesto de manifiesto cómo ese proceso nace de una necesidad dentro de las políticas neoliberales: "para abordar la deserción del Estado frente a obligaciones que han sido declaradas básicas en relación al desarrollo de las artes, la 'sociedad civil' del arte se ha organizado con el objeto de montar unos dispositivos y articular [nuevas] instancias de 'institucionalización'".

\section{Manifiestos de independencia: la ciudad de Lima}

La ciudad de Lima ha sido uno de los contextos más prolíficos para estas prácticas, muchas de las cuales han surgido como respuesta directa a la ausencia de un museo de arte moderno o contemporáneo. ${ }^{1}$ Las producciones del grupo Arte Nuevo, que en 1966 había nombrado una ferretería semiabandonada como sede del Museo de Arte Moderno de Lima, o las intervenciones de Francisco Mariotti, se configuraron tempranamente como respuestas críticas frente a esta ausencia en el paisaje museal peruano. Más contemporáneamente, nos detendremos en dos protagonistas principales de estas estrategias: el trabajo de la artista Sandra Gamarra, y su Museo de Arte Contemporáneo de Lima (LiMAC), y el Micromuseo, del investigador Gustavo Buntinx, desarrollado desde mediados de los años ochenta. Por otro lado, si bien no responde propiamente al contexto limeño, entre estas estrategias también puede incluirse el proyecto del Museo de Arte Contemporáneo de Puno (Puno MAC), del artista César Cornejo, quien propone un museo construido con sedes temporales en casas remodeladas de habitantes de esa ciudad.

Existe, a su vez, toda una serie de prácticas microinstitucionales que no refieren de manera explícita la ausencia de museos de arte, sino que orientan sus problemáticas directamente a exclusiones sociales o a resignificaciones de producciones de la cultura visual. Son, por ejemplo, los casos de los museos Travesti (2003) de Giuseppe Campuzano, Neo-Inka de Susana Torres Márquez y Hawai de

\footnotetext{
${ }^{1}$ Es necesario aclarar que el paisaje museal limeño se ha modificado en los últimos años por las estrategias Ilevadas a cabo desde el Museo de Arte de Lima, las cuales, sin embargo, no han cancelado las discusiones sobre la ausencia del MAC-Lima a la que se hace referencia en este texto.
}

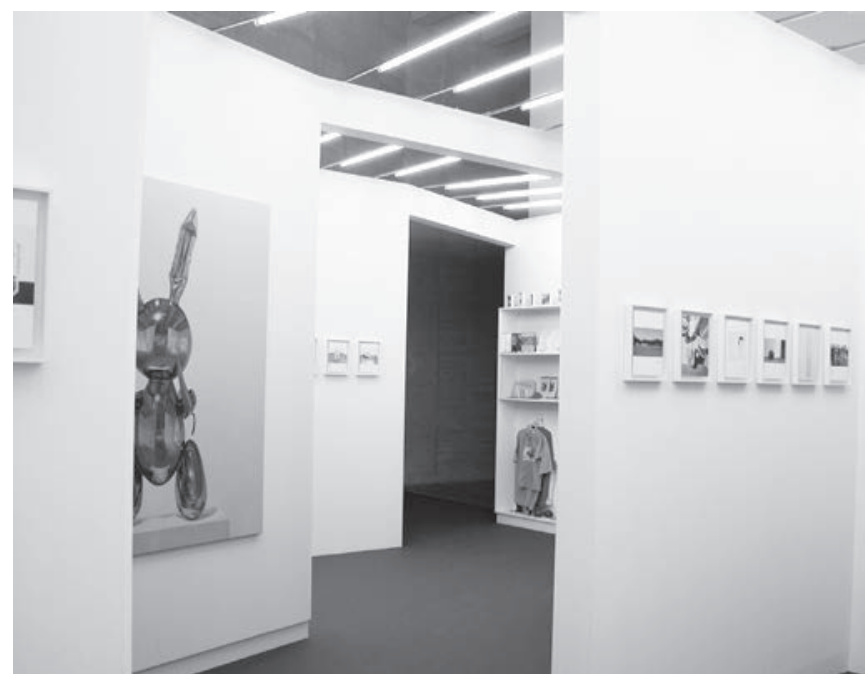

FIGURA 1. Presentación del LiMAC en el Museo de Arte Contemporáneo de Castilla y León, España (Fotografía Sandra Gamarra, 2005; cortesía: LIMAC).

Fernando Bryce, presentado por primera vez en el marco de Micromuseo en 1999.

El LiMAC de Sandra Gamarra es sin duda una de las experiencias museotópicas más interesantes. También con base en el vacío museal, la artista articula un espacio de relación que, si bien no existe en una sede fija, se "presenta como un museo real a través de las diversas maneras en que los museos reales llegan a Lima; es decir, mediante souvenirs, catálogos e impresos" (Gamarra 2005).

La primera manifestación del LiMAC fue la circulación de objetos de recuerdo del museo mismo, al que fue incorporando una colección conformada, con base en imágenes tomadas de catálogos de arte, por óleos de la propia Gamarra: "La colección del LiMAC, materializada por medio de la pintura, es real. La pintura resulta el medio elegido para crear obras reales a partir de las imágenes impresas de las obras originales" (Gamarra 2005). La base principal del museo se articula en función de su página web, aunque esto no significa que deba considerarse como un museo online, ya que realiza exposiciones de su propia colección en diversos lugares físicos de exhibición.

Así, desde el año 2002 el LiMAC ha problematizado los distintos aspectos que conforman el museo, desde los souvenirs y las visitas guiadas, hasta la colección y la librería. Inicialmente exhibido como "museo-manta", en él los souvenirs y objetos se mostraban emulando la figura del vendedor ambulante urbano, que hace suyo un lugar en la ciudad para ofrecer sus mercancías. Esta práctica, típica en todos los países latinoamericanos, da cuenta no sólo del comercio ambulante sino también de las imitaciones de las marcas reconocidas que se ponen a la venta. La firma internacional de indumentaria o tecnología es apropiada en la periferia por la comercialización de la imitación. 


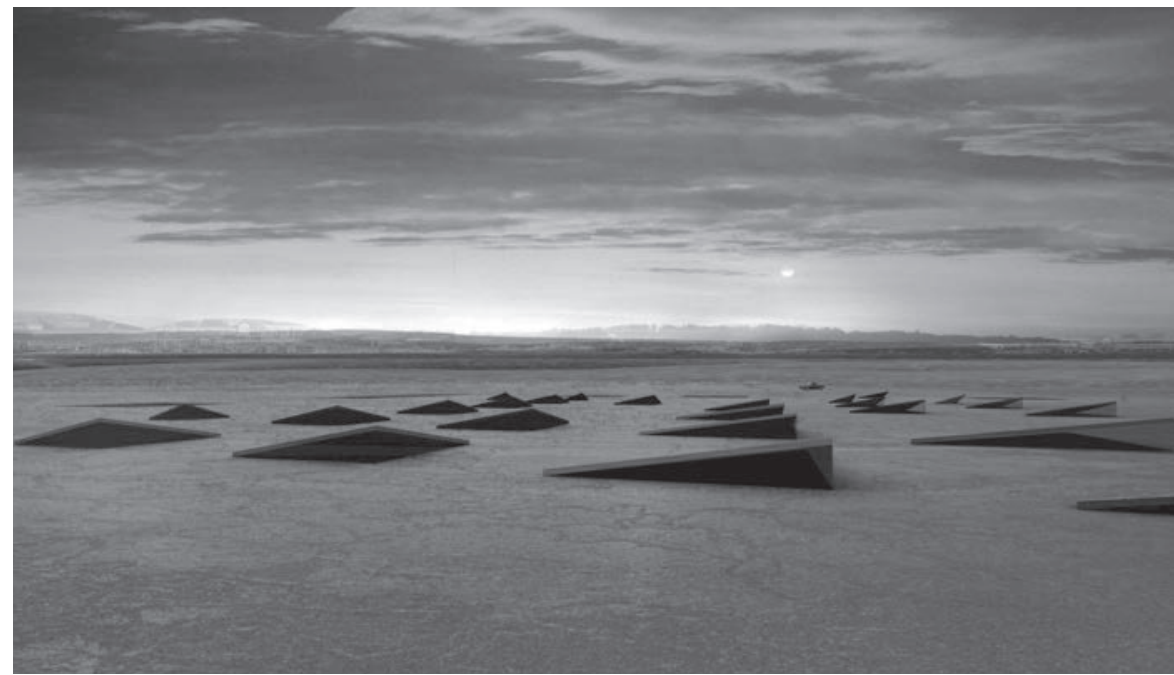

FIGURA 2. Proyecto arquitectónico LimAC, Estudio Productora, México (Render Estudio Productora, 2006; cortesía: LiMAC).

Esta institucionalidad-otra se configura también en su proyecto arquitectónico. El LiMAC propone una edificación invisible, un espacio enterrado en el desierto ubicado al lado de una de las carreteras de acceso a la ciudad de Lima, en contraposición al museo-firma que se plantea como un acento arquitectónico en el espacio urbano. A la visibilidad del museo global Gamarra contrapone la fisura en la tierra misma del desierto peruano.

Si, como lo plantea Hal Foster (2004: 37), los museos de arte contemporáneo utilizan las dimensiones del arte de posguerra y, como en los casos Guggenheim, hacen de lo gigantesco lo espectacular, Gamarra propone un museo sin fachada: donde todo lo que puede verse es simplemente desierto. Al museo-marca como mecanismo de gentrification en la ciudad contemporánea le opone un museo fuera de la ciudad, y así hace de esa arquitectura la posibilidad misma de una museotopía crítica.

La segunda experiencia a la que haré referencia es la que Gustavo Buntinx ha desarrollado desde mediados de los ochenta, sin duda una de las museotopías más complejas del ámbito latinoamericano. Micromuseo se ha convertido en una de las estrategias críticas más visibles, que, por ejemplo, ha tenido un lugar protagónico en la Trienal de Chile (2009) y en los más variados circuitos de exhibición, y ha permitido, a su vez, vehiculizar otras operaciones museotópicas, como el Museo Hawai de Fernando Bryce. Micromuseo, al igual que el LiMAC de Gamarra, es una estrategia surgida desde la ausencia de un museo de arte moderno o contemporáneo. Pone en juego, asimismo, otras dos problemáticas comunes a las museotopías latinoamericanas: la reflexión sobre los procesos económico-sociales y el papel del campo artístico.

Para el primero de los elementos del par, Micromuseo plantea varias cuestiones. La carencia de una institución da cuenta de una ausencia más importante: la de una iconografía que responda a los sectores excluidos de la sociedad peruana. Una institución que siguiese la imagen clásica de museo nacional buscaría cancelar las fricciones y las contradicciones de la sociedad; Micromuseo, por el contrario, utiliza estas últimas como "principio dinamizador". Las palabras de Anderson reaparecen nuevamente en Buntinx (2006b: 175), en tanto que concibe la práctica artística como "un agente crítico de una ciudadanía nueva" en una "comunidad inimaginada donde ningún presente cancela todos los pasados irresueltos que se derraman sobre nosotros".

Micromuseo se configura como una estrategia itinerante: no se trata simplemente de acumular los objetos, sino de hacerlos circular. En este sentido problematiza también la tensión entre la ciudad "modernizada", utopía de los procesos neoliberales de la década de 1990, y la ciudad de los gigantescos mercados callejeros, traspasada por la iconografía completamente diversa de un pop desenfadado, insolente y salvaje. En palabras del propio Buntinx (2006b: 175): "una musealidad promiscua, donde las obras Ilamadas artísticas coexisten con productos masivos u objetos reciclados, además de notables ejemplos de la múltiple creatividad popular".

Por otro lado, las prácticas de Buntinx aluden directamente a la realidad política peruana, dos de las cuales resultan paradigmáticas: la escopeta artesanal "hechiza", recientemente expuesta en la Trienal de Chile y que pertenece a la colección de Micromuseo. Este objeto lo construyó un campesino de Ayacucho, finalmente asesinado por Sendero Luminoso, para su defensa personal. El otro ejemplo de la vinculación directa con la realidad política peruana fue la exposición Emergencia artística. Arte crítico 1998-1999. Aquí Micromuseo tomó como lugar de exhibición una mansión colonial destruida, ubicada en las cercanías del convento de San Francisco. La exposición buscaba, según Buntinx, contraponerse a los centros de poder en Lima y ejercer una resistencia simbólica al gobierno de Fujimori.

Ahora bien, junto con una reflexión sobre los procesos políticos contemporáneos, Buntinx también coloca su museotopía como posición crítica al sistema de circulación nacional y global del arte:

Su horizonte no es global sino "glocal", por utilizar un término de relevancia para discusiones como las que afrontamos. Su fantasía originaria es la de un museo rodante, un museo ambulante, sin directores ni administradores, pero con choferes y cobradores, con "palancas", dateros, ruteros, 
mecánicos. Con paraderos oficiales y otros clandestinos. Con unidades formales y otras "piratas". Con flexibilidad infractora otorgada por licencias de manejo artístico que no reconocen normas establecidas de tráfico cultural, modificando los modelos primermundistas que los informan, subvirtiendo hasta las estrategias transnacionales de subversión cultural. De la apropiación a lo (in)apropiado, del pop cosmopolita al pop achorado, de la deconstrucción a lo reconstructivo (Buntinx 2006b: 174).

Las estrategias en la periferia se rearticulan, se reapropian y se repolitizan. El lema de Micromuseo: "al fondo hay sitio", tomado de los "llenadores" de los transportes públicos, da cuenta de que al momento de elegir las producciones no hay un criterio exclusivo. Esta posición pretende poner en circulación prácticas artísticas sin espacios de exhibición en tanto "preservación, investigación y promoción de nuestra cultura crítica" (Buntinx 2006b: 183).

Justo Pastor Mellado, en El curador como productor de infraestructura (2002), al cual también refiere Buntinx, hace una distinción entre el curador de servicio y el curador como productor de infraestructura. En el primero de los casos el guión curatorial sería una "edición local de un guión asignado por los criterios de validación de las industrias de exposiciones" (Mellado 2002), "relativas —agregará el autor - al fortalecimiento de la 'vanidad', tanto de los Estados como de los multinacionales". Si esta alternativa supone una relación de subordinación de los modelos historiográficos y curatoriales de la periferia respecto del centro, el curador como creador de infraestructura subvierte esa relación, la deconstruye para crear nuevos relatos:

[...] el curador como productor de infraestructura es aquel que debe subordinarse a este objetivo de recuperación del síntoma; de las obras como síntoma de las identificaciones en curso, inscritas sobre una trama estratificada de determinaciones orgánicas, musealmente determinadas (Mellado 2002: 11)

Si el curador de servicio es hablado "por la institución", el curador de infraestructura opera desde la ditmensión: dicho en términos simples, "desde y por el deseo de casa" (Mellado 2002:11). Así, nuevamente, no sólo se pone en relevancia la importancia crítica de las prácticas curatoriales sino cómo éstas generan deseo a partir de tener su origen en una ausencia, como la de un museo de arte moderno, o de la visibilidad de determinadas producciones.

\section{Estrategias ante la crisis: Buenos Aires}

El panorama en Buenos Aires no cuenta con museotopías con las características desarrolladas por Buntinx o Gamarra. Sin embargo, surgen varias prácticas que, si bien son diferentes, resultan interesantes en función de la utilización de estrategias microinstitucionales como mecanismos críticos.

Analizaremos dos producciones artísticas que resultan significativas en tanto posibilidades de reflexión sobre el papel del museo como forma crítica en el contexto latinoamericano: la experiencia Ferro-carriles Argentinos, de Patricio Larrambebere, y Ensayo sobre un museo libertario, de Magdalena Jitrik. Ambas estrategias intervienen museos-archivo de algún modo olvidados, que no pertenecen al circuito del arte, y los utilizan como forma de contraponer los inicios de la crisis frente a utopías modernas (González 2010).

La primera de estas estrategias, Ferro-carriles Argentinos, realizada en el Museo Nacional Ferroviario en 1998, se inscribe en un contexto más amplio de acciones elaboradas por Patricio Larrambebere antes y después de esta exposición. Entre ellas cabe destacar la creación, en 1998, de Abte, una agrupación que buscaba mantener la memoria de los boletos tipo Edmondson usados antiguamente en el sistema ferroviario, las "24 reflexiones sobre nuestro presente ferroviario", de 1999, y la muestra, en el año 2002, Abte: Sede temporaria, en el Museo de Arte Moderno de Buenos Aires.

De esta serie de intervenciones nos interesa resaltar varios elementos. En primer lugar, su objetivo principal era posicionarse críticamente ante el proceso de privatización del sistema ferroviario, que implicó el aislamiento de ciudades del interior del país y la pauperización de las comunicaciones dentro de la ciudad. En este contexto, en la muestra Ferro-carriles Argentinos, Larrambebere recupera imágenes y archivos, y realiza sus propias producciones con representaciones de las estaciones del conurbano bonaerense. La inclusión de estas últimas, realizadas en óleo sobre lienzo, representaba la contraparte de las protestas sociales generalizadas en la Capital Federal llevadas a cabo por sectores de la provincia excluidos por las políticas neoliberales.

En segundo lugar la exposición tiene lugar en el Museo Nacional Ferroviario, donde las obras adquieren sentido en el propio contexto y, a su vez, avivan la potencia crítica del mismo museo (González 2010: 21-22). Larrambebere pone en juego la obra en su vinculación con el lugar y lo hace a partir de su intervención dentro de un museo que no pertenece al circuito del arte. Por otro lado, esta misma estrategia se completa con la creación de una agrupación que colecciona boletos, una exposición en el Museo de Arte Moderno y una intervención urbana.

En sus prácticas, el tren deja de ser para el artista un medio de transporte o una mera metáfora de exclusión, para convertirse en un vínculo afectivo con una actividad perdida, con una estación abandonada o, como en el caso de Abte, con un antiguo sistema de impresión de boletos. El desmantelamiento del sistema ferroviario es, a su vez, la desarticulación de la utopía moderna de la Argentina de principios de siglo XX, elemento que se recupera a finales 


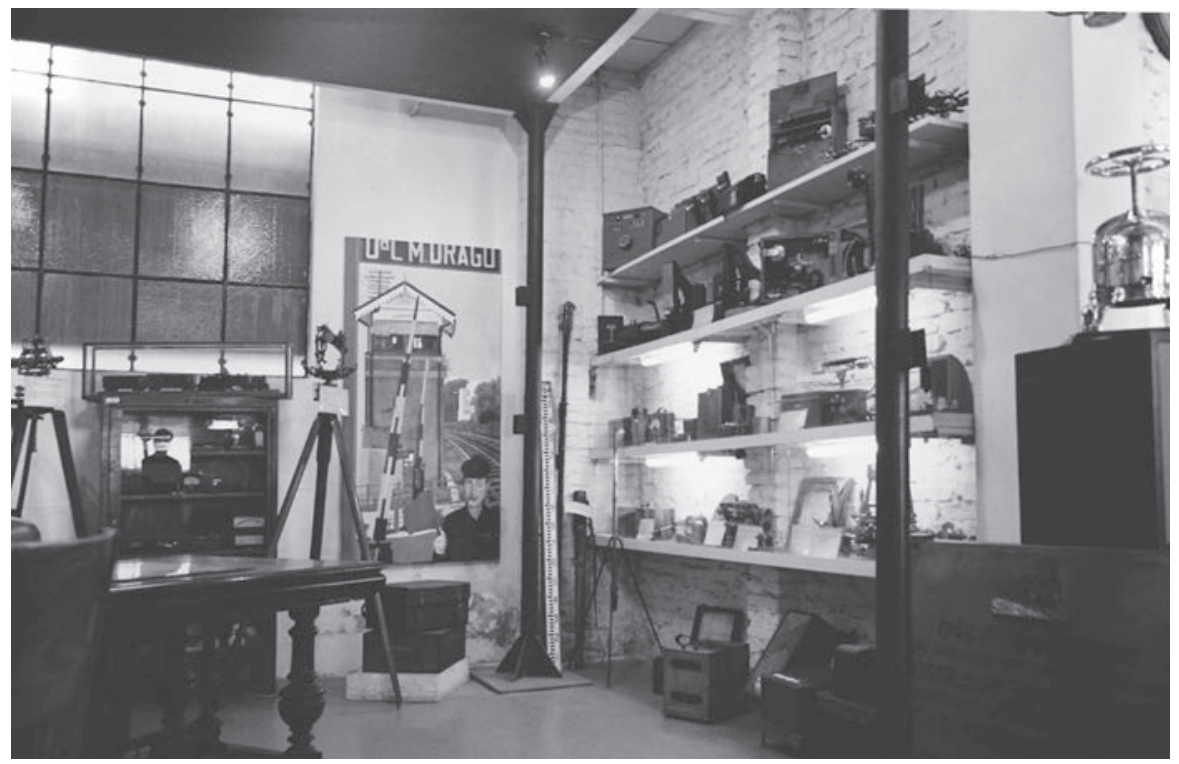

FIGURA 3. Ferro-carriles Argentinos, Museo Nacional Ferroviario, Argentina (Fotografía Patricio Larrambebere, 1998; cortesía del artista).

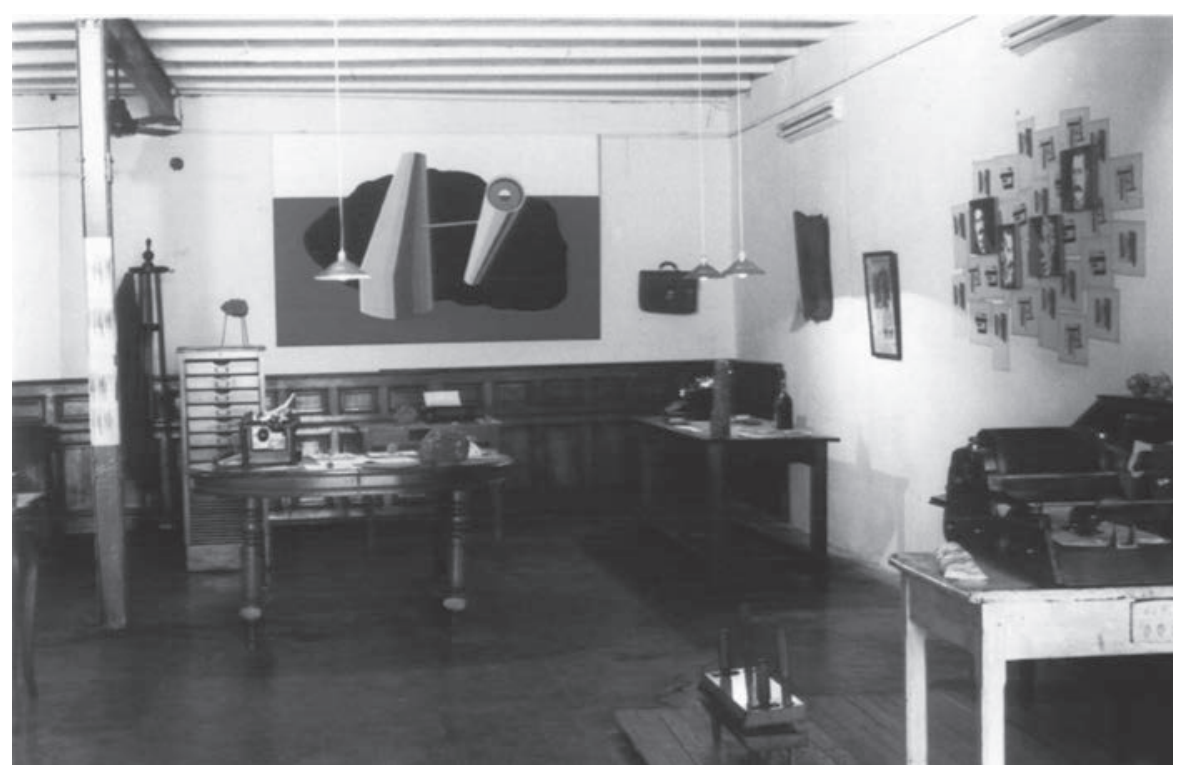

FIGURA 4. Ensayo de un Museo Libertario. Federación Libertaria Argentina (Fotografía Magdalena Jitrik, 2001; cortesía de la artista).

de la década de 1990, frente a los inicios de la crisis de otro modelo, en este caso el liberal.

La segunda de las producciones que destacaremos es la que Magdalena Jitrik realiza en la sede de Federación Libertaria Argentina (2000-2001), una agrupación anarquista con gran preeminencia política durante todo el siglo XX. En el contexto del supuesto fin de las ideologías, Jitrik busca reflexionar sobre las actividades de los anarquistas a partir de un "ensayo de un museo". Éste, en palabras de Valeria González (2010), no se posiciona como lugar meramente de conservación, sino como un proceso de repolitización y revitalización de una de las grandes opciones de transformación política desarrolladas durante el siglo XX.

Ambas producciones tienen puntos en común. En primer lugar, no son realizadas como respuesta directa a la crisis económica, política y cultural argentina del 2001, sino con anterioridad a ésta, dentro de un "contexto de crisis" que ya se había puesto en juego en las problemáticas artísticas antes de los hechos de diciembre. Dentro de este ambiente los artistas intervienen dos lugares: un museo y una federación, en función de prácticas atravesadas anacrónicamente - en el sentido elaborado por Didi-Huberman - para plantear críticas directas a las políticas neoliberales desarrolladas durante la década de 1990.

En segundo lugar, ambos buscan "reavivar la potencia crítica" de los lugares de circulación, denunciando su neutralidad y utilizando estrategias que apuntan directamente a los museos: en el caso de Larrambebere, interviniendo un museo ya existente $y$, en el de Jitrik, creando un "ensayo" de museo dentro de la Federación. Ninguno de los dos buscó erigir esas instituciones como lugares de certidumbre, sino que intentaron recuperar experiencias políticas y de desarrollo desarticuladas durante el periodo neoliberal; obligando a los espectadores a "que elaboren su propia traducción para apropiarse de la "historia" y hacer de ella su propia historia" (Rancière 2010: 27).

Tanto Larrambebere como Jitrik reactualizan, en un momento en que la ciudad era vista como lugar de crisis, dos utopías modernas que tuvieron gran importancia en las transformaciones políticas de principios de siglo: los ferrocarriles y el anarquismo. El primero proponía una lectura de la ciudad en función de la política "modernizadora" de la Argentina agroexportadora; el ferrocarril construía un recorrido de la ciudad que se vinculaba directamente con esa estructura económica. El segundo, la exposición de Jitrik, muestra a la ciudad de las protestas, de las movilizaciones, como lectura disímil de lo urbano frente al modelo de Argentina presentada por Larrambebere.

En un artículo publicado en la revista AdVersus, Fredric Jameson (2006) sostenía que las utopías surgían 
al momento de la suspensión de lo político: cuando el sistema parece inamovible, se abre el momento utópico: "en esa distancia entre el sistema inmutable respecto a la agitación turbulenta del mundo real parece abrir un momento de libre despliegue de ideaciones y creaciones en la propia mente o la imaginación" (Jameson 2006). Al momento en que el sistema mismo está en verdadero peligro o en vías de perder su legitimidad, para Jameson las reivindicaciones se vuelven mucho más concretas, y la política, de algún modo, posible.

Las dos últimas prácticas artísticas que he mencionado podrían entenderse en los términos a los que se refiere Jameson. A finales de la década de 1990 las protestas sociales se intensificaron, pero las posibilidades ciertas de una crisis completa del sistema, de su pérdida de legitimidad y de su crisis radical, sólo se pondrían en juego unos pocos años después. Larrambebere recupera los ferrocarriles como elemento de desarrollo fundamental de la Argentina moderna y Jitrik reaviva la memoria de un movimiento de transformación radical del sistema; ambos desde las posibilidades críticas de un museo ya establecido, pero "olvidado", y de un "ensayo museal" en el contexto de una Federación.

Así como en el resto de las museotopías mencionadas, en estas dos estrategias también puede verse la problemática referida al campo del arte y sus procesos legitimadores durante los noventa en Buenos Aires. Ni las obras pictóricas de Larrambebere ni las de Magdalena Jitrik se correspondían "con las apropiaciones desenraizadas y autocomplacientes del arte posmoderno" (González 2010: 36). En primer lugar, no entraban dentro del parámetro estilístico de las producciones que se realizaban en el Centro Cultural Rojas, que fue, durante los años noventa, una de las instituciones legitimadoras más importantes del campo artístico porteño. Pero, en segundo lugar, tanto la obra de Larrambebere como la de Jitrik continúan desarrollándose luego de los hechos del 19 y el 20 de diciembre de 2001, y entran en contacto directo con los colectivos artísticos que tuvieron amplia visibilidad y participación en las protestas sociales de aquellos tiempos.

\section{Conclusión}

Este texto surge a partir del desafío que significa encontrar paralelismos entre las producciones de creación "microinstitucional" en el campo del arte latinoamericano durante los últimos años. La pregunta principal radica en plantear por qué el museo, una institución ligada tan fuertemente a la modernidad, puede utilizarse como una herramienta crítica a finales de siglo xx.

En primer lugar, aquí se ha referido la crítica tradicional a los museos que se centra en su vinculación con los procesos de formación del Estado nacional, y, fundamentalmente, como mecanismos dentro de los procesos de formación vertical de identidad. Muchas de las estrategias de las primeras operaciones de crítica institucional internacional hacen hincapié sobre este aspecto. Sin embargo, dentro del contexto latinoamericano, el campo del arte se ha configurado de un modo distinto, y las prácticas museotópicas, antes que problematizar la relación entre el museo y la nación, pueden nacer ante la ausencia de un museo de arte, como es el caso de Micromuseo o del resto de las experiencias limeñas.

En segundo lugar, se ha hecho referencia a dos contextos disímiles, tomando casos modélicos para cada una de estas ciudades. Si bien no se trata de una enumeración exhaustiva, ni pretende serlo, el objetivo se centró en poder analizar comparativamente estas diversas estrategias para pensar cómo operan dentro del contexto de los procesos políticos contemporáneos. Justamente la vinculación de estas prácticas con el contexto político regional nos lleva a subrayar sus características particulares respecto de otras estrategias de creación institucional, como las desarrolladas por Marcel Broodthaers y su Musée d'Art Moderne, Département des Aigles, o de otras prácticas tradicionales de crítica institucional. Hemos planteado, entonces, dos problemáticas comunes a estas estrategias: por un lado, la reflexión sobre los procesos de desmantelamiento del Estado y de cómo en América Latina aparecen procesos políticos de "modernización", vinculados con el neoliberalismo, que implicaban la exclusión de grandes sectores de la sociedad; y, por el otro, el cuestionamiento sobre cómo estas operaciones controvierten las relaciones internas en el campo del arte y los procesos de legitimación-exclusión que se generan por dentro del mismo.

Por su extensión, el artículo ha dejado pendientes dos ámbitos de análisis. Uno, la incorporación de otras ciudades latinoamericanas donde también pueden encontrarse estrategias similares durante el mismo periodo. Esto permitiría, por ejemplo, investigar cómo se vinculan las distintas prácticas museotópicas entre sí. Al segundo correspondería analizar cómo estas estrategias "itinerantes" han circulado desde los años noventa por los espacios de exhibición, lo que llevaría a estudiar cómo estas operaciones han sido exhibidas en otras ciudades y en bienales de arte o exposiciones de arte latinoamericano contemporáneo. Este último aspecto haría posible abordar, por ejemplo, cómo se ha interpretado y resignificado cada una de estas obras en los diversos espacios.

Finalmente, estas estrategias representan un elemento que necesariamente ha de abordarse comparativamente para poder entender cómo se van articulando estas operaciones que, parafraseando a Gerardo Mosquera, conforman el paradigma de un arte que no se construye ni para lo local ni para lo global, sino "desde" América Latina, con sus fracturas, sus apropiaciones y sus desafíos. 


\section{Referencias}

Bourdieu, Pierre y Alain Darbal

2003 El amor al arte. Los museos europeos y su público, Barcelona, Paidós.

Buchloh, Benjamin

1990 "Conceptual Art 1962-1969: From the Aesthetics of Administration to the Critique of Institutions", October, 55:105143.

Bürger, Meter

1997 Teoría de la vanguardia, Barcelona, Península.

Buntinx, Gustavo

2006a "Communities of Sense / Communities of Sentiment: Globalization and the Museum Void in an Extreme Periphery", en Ivan Karp, Corinne A. Kratz, Lynn Szwaja y Tomás Ybarra-Frausto (eds.), Museum Frictions. Public Cultures/ Global Transformations, Durham y Londres, Duke University Press, 218-246.

2006b "Una musealidad mestiza, una musealidad promiscua, nuevas rutas para un micromuseo", ponencia presentada en el encuentro, 10000 francos de recompensa (el museo de arte contemporáneo vivo o muerto, Universidad Internacional de Andalucía, Jaén, 15 y 18 de diciembre.

2009 "Que la diferencia refulja", Revista Ramona 89:3944.

Connor, Walker

1998 Etnonacionalismo, Madrid, Trama.

Duncan, Carol

1991 "Art Museum and the Ritual of Citizenship", en Ivan Karp y Steven Lavine (eds.), Exhibiting Cultures. The Poetics and Politics of Museum Display, Washington / Londres, Smithsonian Institution Press, 88-103.

Duncan, Carol y Wallach, Alan

1978 "The Museum of Modern Art as Late Capitalist Ritual", Marxist Perspectives 4:28-51.

1980 "The Universal Survey Museum", Art History 3: 447-469.

Foster, Hal

2001 El retorno de lo real. La vanguardia a finales de siglo, Madrid, Akal.

2004 Diseño y delito y otras diatribas, Madrid, Akal.

Fraser, Andrea

2005 "From the Critique of Institutions to an Institution of Critique", Artforum 44: 278-283.

Gamarra, Sandra

2005 "El LiMAC en el Musac", en Catálogo Emergencias, León, Museo de Arte Contemporáneo de Castilla y León, do- cumento electrónico disponible en [http://www.li-mac.org/ index.php?id=41], consultado en noviembre del 2011.

González, Valeria

2010 En busca del sentido perdido, 10 proyectos de arte argentino. 1998-2008, Buenos Aires, Editores Papers.

Holmes, Brian

2007 "Investigaciones extradisciplinarias. Hacia una nueva crítica de las instituciones", Brumaria 8: Arte y revolución, documento electrónico disponible en [http://brumaria.net/ publicacionbru8.html], consultado en noviembre del 2011.

Jameson, Fredric

2006 "La política de la Utopía", AdVersus, Revista de Semiótica 6-7, agosto-septiembre, documento electrónico disponible en [http://www.adversus.org/indice/nro6-7/articulos/ articulo_jameson.htm], consultado en noviembre del 2010. Medina, Cuauhtémoc

2002 "Pseudomuseos: sobre el Museo Salinas y otros ejemplos de la museografía parasitaria en México", ponencia presentada en el Aula Magna del Centro Multimedia del Centro Nacional de las Artes, México, 27 de abril.

Mellado, Justo Pastor

2002 El curador como productor de infraestructura, documento electrónico disponible en [www.sepiensa.cl/ed_digital/mellado_de_un_modo_elusivo.html], consultado en julio del 2011.

2003 "Historias locales, archivos, musealidad", Huellas 3:5054.

Nowotny, Stefan

2006 Anticanonización. El saber diferencial de la crítica institucional, documento electrónico disponible en [http://transform.eipcp.net/transversal/0106], consultado en noviembre del 2010.

Rancière, Jacques 2010 El espectador emancipado, Buenos Aires, Manantial.

Raunig, Gerald

2009 "Instituent Practices, No. 2: Institutional Critique, Constituent Power and the Persistence of Instituting", en Gerald

Raunig y Gene Ray (eds.), Art and Contemporary Critical Practice: Reinventing Institutional Critique, Londres, Mayflybooks, 173-185.

Smith, Anthony

1997 La identidad nacional, Madrid, Trama.

Steyerl, Hito

2006 La institución de la crítica, documento electrónico disponible en [http://transform.eipcp.net/transversal/0106], consultado en noviembre del 2010. 


\section{Resumen}

En este ensayo se ponen en relación prácticas artísticas contemporáneas que se apropian de la noción misma de museo de arte para redimensionar su sentido y proponer modelos museológicos alternativos. El análisis se circunscribe a las producciones de artistas en dos contextos urbanos específicos: Lima y Buenos Aires. En la primera ciudad, se examinan las prácticas de creación institucional denominadas "museotopías", que surgen ante la falta de museos de arte contemporáneo en la ciudad. Luego, se exploran dos estrategias en Buenos Aires que pretenden reconfigurar objetivos y estrategias concretas de museos existentes. Ello sirve para plantear dos problemáticas fundamentales que se consideran comunes a estas estrategias. En primer lugar, la reflexión sobre los procesos de desmantelamiento del Estado y de exclusión de grandes sectores de la sociedad. En segundo lugar, la forma en la que estas operaciones cuestionan las relaciones internas en el campo del arte y los procesos de legitimación-exclusión que se generan por dentro del mismo.

Palabras clave

Museo, crítica institucional, arte contemporáneo.

\section{Abstract}

This essay analyzes contemporary artistic practices that appropriate the notion of an art museum to reshape its meaning and propose alternative museological models. The focus of the critique is on artists' productions from two specific urban contexts: Lima and Buenos Aires. In the former, creative institutional practices called "museotopías" are examined, resulting from a lack of contemporary art museums in the city of Lima. In the latter, two strategies that reconfigure concrete objectives and strategies of existing museums in Buenos Aires are explored.

The analysis poses two fundamental problems that are common to both strategies: on one hand, reflection on the process of dismantling the State and the exclusion of large sectors of society, and on the other hand, the way in which these works question the internal relation in the art world and the processes of legitimation and exclusion that are generated within it.

\section{Keywords}

Museum, institutional critique, contemporary art.

Título en inglés: "The Museum through the artist: institutional strategies in Lima and Buenos Aires" 